\title{
Visibilidad del discurso político agresivo. Una interpretación pragmático-cognitiva basada en una valla publicitaria anti-obama Manuel Balsera FernÁNDEZ ${ }^{1}$ \\ Universidad De Córdoba (España)
}

Recibido: $13 / 06 / 2013$

Aceptado: 30/04/2014

\section{Resumen}

El propósito del artículo consiste en describir, debatir e interpretar una valla publicitaria exterior, como una representación comunicativa multimodal, inscrita en una campaña política de carácter preelectoral. Ésta no está exenta de tensión polarizante, por lo que hemos caracterizado el discurso político-publicitario de potencialmente agresivo. Partimos de esta presuposición al considerar, como traductores, que jugamos el papel de destinatario en una comunicación de segundo orden que se produce a causa de nuestra pertenencia a otro entorno cognitivo, cultural y emocional. Consideramos que la intencionalidad básica de esta valla publicitaria tiene la pretensión comunicativa de estigmatizar al adversario político y al partido que éste representa. Desde la perspectiva de la Teoría de la Relevancia de Sperber y Wilson $(1986,1995,1998$, 2002, Wilson \& Sperber 2012) se delimita la comunicación como un ejercicio cognitivo - que se viene a corresponder con la consecución de una información relevante o pertinente- que nos permite interactuar con los símbolos y con las palabras que de manera ostensiva nos envía el emisor. Para llegar a comprender las peculiaridades de este discurso político debemos interpretar la información procedente de sus códigos especiales y pasarlos por el tamiz de nuestra capacidad inferencial. La interpretación es un proceso cognitivo dinámico que nos permitirá construir un conjunto de conceptos ad hoc dependiendo de las nociones de efecto contextual y de coste de procesamiento siguiendo la Teoría de la Relevancia.

Palabras clave: Pragmática; Relevancia; Barack Obama; Multimodalidad; Discurso político agresivo.

\section{The visibility of aggressive political discourse. A pragmatic-cognitive interpretation of one anti-Obama's poker racist billboard}

\begin{abstract}
The aim of this article is to describe, discuss and eventually interpret a multimodal communicative representation of an external billboard. It falls within the context of a pre-electoral political campaign under considerable strain and polarized opinions. We have characterized its political discourse as potentially aggressive. We start from this assumption because, as translators and cognitive interpreters, we are playing the role of receptor on a secondary communication message simply because we are members of another cultural, cognitive and emotional environment. We believe that the basic attempt of the billboard is to stigmatize the political opponent and the party he is representing. Using Sperber and Wilson's Relevance Theory as a framework (1986, 1995, 1998, 2002, Wilson \& Sperber 2012), communication is best described as a cognitive computation -which aims at the achievement of relevant information - that allows us to interact with the symbols and words ostensibly sent out by the communicator. In order to understand the features of this political discourse, we interpret the information drawn from their specific codes and then we sieve them through the filter of our inference ability. Interpretation as a cognitive dynamic process should allow us to construct a set of $a d$ hoc concepts depending on the notions of contextual effect and processing cost put forward by Relevance Theory.

Keywords: Pragmatics; Relevance; Barack Obama; Multimodality; aggressive political discourse.

\footnotetext{
${ }^{1}$ Manuel Balsera Fernández, email: mbalseraf@terra.com: Grupo de Investigación «Estudios de Traductologia, Discurso y Cognición». PAIDI: HUM887. Universidad de Córdoba. Director: Prof. Dr. Vicente López Folgado.
} 


\section{Introducción}

Hubo una época en que se hablaba de la publicidad subliminal, pero ahora de lo que se habla es de la anti-publicidad y de la publicidad agresiva. La valla publicitaria que nos proponemos estudiar está realizada estilísticamente como una viñeta humorísticopolítica de carácter sarcástico y violento, cuyo framing de entrada es el de una habitación con impactos de bala en sus paredes. La viñeta está repleta de estímulos ostensivos de naturaleza fundamentalmente visual con gran contenido simbólico, cuya intencionalidad es exteriorizar una cosmovisión radical de ideología afín. Es preciso señalar que tal visualidad pertenece al campo de las prácticas comunicativas que generan significado cultural. Por esta razón queda sujeta a posibles reinterpretaciones emocionales. Desde una perspectiva pragmática debemos prestar especial atención a dos de sus elementos básicos: el carácter polisémico de las imágenes metafóricas y la ambigüedad o ambivalencia del propio mensaje satírico-político verbalizado. Wilson y Sperber (2004) nos aclaran:

La teoría de la relevancia puede entenderse como el intento de profundizar en una de las tesis fundamentales de Grice: que una característica esencial de la mayor parte de la comunicación humana es la expresión y el reconocimiento de intenciones (Grice 1989: Ensayos 1-7, 14, 18; "Retrospective Epilogue").

Las llamadas «mid-term elections» ${ }^{2}$ de Estados Unidos han sido objeto de interminables debates y de estudios de naturaleza diversa ${ }^{3}$. Cuando se aproximaba el 2 de noviembre de 2010, día de la votación, la campaña electoral se estaba convirtiendo en un combate en el cual algunas personas y grupos políticos ${ }^{4}$ estimaban que en nombre de la Libertad se podía utilizar cualquier medio para ganar votos. La inquina contra el presidente Barack Obama parecía no tener límites. Estos comicios, que tradicionalmente han jugado un papel secundario, adquieren, en esta ocasión, un inusitado valor porque podrían generar una Cámara de Representantes y un Senado hostiles a Barack Obama, a su política de cambio interior y exterior y a todo aquello que el presidente representa, incluido su propio color.

En este contexto de excitación ideológica aparece, entre otras iniciativas, la página Web billboardsagainstobama.com desde la que se pedía contribuciones dinerarias para sufragar vallas publicitarias como un modo práctico y eficaz de que los estadounidenses descontentos pudieran unirse a la batalla política contra Barack Obama. De esta manera podrían ser vistos y oídos antes de que las reformas del presidente lograran triunfar y fuese demasiado tarde para detenerlas. Desde una perspectiva cultural o de antropología política las vallas son, sin duda, la forma más típicamente americana empleada para

\footnotetext{
${ }^{2}$ Se elige a la totalidad de los 435 miembros de la Cámara y una tercera parte de los 100 miembros del Senado, más los escaños que haya que completar por fallecimiento o retirada del anterior ocupante. http://www.elpais.com/articulo/internacional/Claves/elecciones/2010/ elpepuint/20101031elpepuint_10/Tes

${ }^{3}$ Uno de los que hemos consultado es el de Mark Franklin y Till Weber. The Structuring Effect of First Order Elections. Véase en http://www.eui.eu/Personal/Franklin/StructuringEffect.pdf

${ }^{4}$ Se dio la especial circunstancia de que a estas elecciones concurrió por primera vez el Tea Party, un conglomerado ultra conservador que nació como un movimiento contra los impuestos y la demanda de reducción de un gobierno que consideran demasiado grande.
} 
la publicidad y, en su larga trayectoria, muchas de ellas han resultado muy polémicas y controvertidas. La respuesta a este llamamiento fue contundente, de manera que la campaña gozó de gran éxito. En algunos estados del país se desplegaron gran cantidad de vallas publicitarias anti-Obama desatando la polémica por sus mensajes de indudable carácter agresivo ${ }^{5}$. La idea básica subyacente en este tipo de proyectos consiste en convertir la convocatoria electoral de mitad de mandato en un referéndum en contra de la revalidación en las cámaras del presidente Obama y de sus reformas.

La publicidad así entendida, lejos de ser simplemente informativa, es persuasiva y manipulativa y está dirigida contra el otro (the outgroup). El antagonismo intergrupal va más allá de lo que entendemos por sátira política y moral basando en este rasgo agresivo su eficacia comunicativa, posible semilla o embrión de un aprendizaje vicario. Especialmente si consideramos que la buena imagen de los políticos es esencial para la «eutaxia» o buen gobierno. El análisis de la gran variedad de mensajes difamatorios y estigmatizantes ${ }^{6}$ que se desplegaron en todas estas vallas excede la longitud de este trabajo y por ello hemos seleccionado como objeto de estudio una unidad publicitaria externa cuyo tópico discursivo es fundamentalmente racista. Por este motivo la hemos etiquetado como «the Obama 's poker racist billboard» basándonos en un titular ${ }^{7}$ que, sobre la misma, apareció en una página Web. Esta valla ubicada originariamente en la Grand Junction de Colorado cumple, a nuestro entender, con dos atrayentes requisitos: a) nos ha parecido la más densa en contenido desde un punto de vista iconográfico e iconológico y b) nos resulta de interés por el hecho de haber desencadenado un encendido debate sobre la libertad de expresión y el discurso del odio «hate speech» ${ }^{8}$. Las caricaturas de Obama que contiene fueron consideradas, por algunos sectores de opinión, como una reminiscencia de racismo ultramontano segregacionista contra el primer presidente negro de EE.UU.

Según estas voces, el discurso icónico-verbal denotado y connotado en esta valla publicitaria venía a rememorar el antiguo sistema de castas estadounidense: «The Jim Crow caste system» ${ }^{9}$ imperante durante el siglo XIX y buena parte del XX. La excepcional polémica suscitada, las supuestas amenazas de muerte recibidas por sus promotores condujo a su desmantelación voluntaria, propiciando un boom informativo

\footnotetext{
${ }^{5}$ He aquí una pequeña muestra de ellos: «Stop Obama’s Socialism!»; «A citizen guide to revolution of a corrupt government. Prepare for war. Live free or die»; «Now it's personal. America's coming for YOU Congress. Vote Liberals Out in 2010! »; «If you're not Outraged. You're not paying attention».

${ }^{6}$ Los autores más relevantes de la teoría del "etiquetamiento estigmatizante" más conocidos son: Becker, Lemert, Erikson, Kitsuse, Tannembaum. Schur y Gusfield.

${ }^{7}$ El titular al que hacemos referencia nos pareció muy adecuado para aludir a esta valla publicitaria y está tomado de la página Web http://www.pokertime.eu/blog/Obama-PokerRacist-Billboard/

${ }^{8}$ Hate speech can be any form of expression regarded as offensive to racial, ethnic and religious groups and other discrete minorities or to women. http://definitions.uslegal.com/h/ hate-speech/.

${ }^{9} \mathrm{Jim}$ Crow was the name of the racial caste system which operated primarily, but not exclusively in southern and border-states, between 1877 and the mid-1960s. Jim Crow was more than a series of rigid anti-Black laws. It was a way of life. Under Jim Crow, African Americans were relegated to the status of second class citizens. Era el imperio de la supremacía blanca.
} 
de considerables proporciones que trajo, como consecuencia, una amplísima difusión nacional. La divulgación de sus mensajes a través de una serie de medios de comunicación de masas, entre los que se incluye Internet, le confirió la categoría de publicidad viral o epidemiología de las representaciones.

\section{Parámetros metodológicos}

Nuestra preocupación metodológica se centrará en explorar algunos elementos de conexión de la Teoría de la Relevancia con otras disciplinas para reflexionar más ampliamente sobre determinados aspectos de nuestro objeto de estudio. Sandra Melo (2010), en relación con la traductología, afirma lo siguiente:

The translation of advertising or any type of marketing material is so complex that even big global companies can get it wrong. Marketing translations require special sensitivity and a deep understanding of the target audience, and need to be able to integrate symbolism, metaphors and emotional intelligence as a part of an appealing and sharp marketing concept. It is essential for your translated documents to effectively convey your message to your audience.

Si ya los artículos comerciales presentan enormes problemas de traducción para su localización. según los diferentes mercados, tanto más lo hace un mensaje de marketing político-electoral de estas características. El traductor, como intérprete cognitivo que es, debe realizar un esfuerzo adicional para obtener la relevancia óptima en una comunicación ostensivo-inferencial de segundo orden. Esta actividad ha de ser previa a su papel de intermediador cultural. Tanaka (1994) al hablar de la relación existente entre relevancia y cognición nos informa que:

Relevance, according to Sperber and Wilson, is the key to human cognition. Their account of communication springs from the belief that the standards which govern inferential communication are based on the nature of human cognition. Humans pay attention to some phenomena rather than others, and Sperber and Wilson's main claim is that humans tend to pay attention to those phenomena which are most relevant to them.

Por consiguiente, si de acuerdo con Gutt (1991), entendemos la traducción como una comunicación secundaria o de segundo orden, el traductor, con objeto de suplir sus carencias como segundo receptor distanciado culturalmente, deberá recurrir a varias disciplinas para llevar su nave a buen puerto, entre las que destacamos: la psicología de la publicidad -como receptor secundario individual-, la sociología de la publicidad -inserta en un sistema social determinado-, la antropología de la publicidad -sujeto situado en una dimensión cultural-, la ciencia política -distintos comportamientos de organizaciones en un país y su ambiente político- . Ulteriormente, tendrá que establecer vínculos de relación para traducir en virtud de esa compleja interpretación -que, a todas luces, consistirá en una «semejanza interpretativa»- porque las proposiciones que se alcanzan mediante las implicaturas serán semejantes, pero nunca iguales al original. Los pensamientos, por ende, obtenidos de esta suerte (meta-representaciones o representaciones mentales individuales) podrán ser semejantes o aproximativos a los 
códigos que los expresan, pero nunca podrán ser idénticos. El contexto posee, por tanto, un importante componente psicológico. Entre un enunciado y el pensamiento expresado por medio de ese enunciado existe semejanza interpretativa si ambos comparten parte de sus contenidos respectivos. En relación con las semejanzas interpretativas en traducción, López Folgado (2010: 58) indica lo siguiente:

En la comunicación no es cuestión de encontrar el (único) estímulo correcto para lo que uno quiere decir. Es fundamental decidir la información que uno puede dar a un receptor concreto y eso depende de quién es y qué bagaje de conocimientos posea. Por ello, en la traducción no se puede contestar a la pregunta: "¿qué serie de suposiciones se han intentado transmitir?" con la simple respuesta: "las mismas que el enunciado original" porque en una situación de comunicación secundaria cambian los contextos.

Por otra parte, Yuste Frías (2008) nos introduce, a través de la reciente noción de paratraducción, en un campo ciertamente novedoso:

El concepto de paratraducción, creado en Vigo, quiere devolver a la imagen y a todo aspecto visual de los paratextos el lugar que merecen en la construcción de sentido simbólico en traducción. Leer e interpretar la imagen resulta esencial a la hora de traducir el texto que la acompaña en un mensaje publicitario: pensar en traducir la imagen en publicidad supone ser consciente de que hay que (para)traducir bien la imagen para traducir mejor el texto. La mirada del traductor, mediador entre diferentes culturas de la imagen, interpreta la dimensión semiótica de la construcción del sentido elaborada en la relación intersemiótica de la pareja texto/imagen de todo mensaje publicitario. Traducir es interpretar, la interpretación es una forma de traducción.

Yuste Frías encuentra las bases de su teoría paratraductora en la deconstrucción Derridiana mientras que nosotros, considerando de gran interés su aportación terminológica (paratraducción), nos inclinamos por un uso del término con un mayor protagonismo del receptor, capaz de aunar el sentido de la mirada semiótica y deconstructora con las ciencias cognitivas y, por ende, con la pragmática en mensajes multimodales. Esta trabazón la proporciona la interpretación meta-representacional propugnada por la Teoría de la Relevancia de Sperber \& Wilson cuándo con gran acierto propugnan: «Relevance is always relevant to a particular person at a particular time» porque, con esto, quieren significar una superación de los esquemas semióticos al incluir, además de la codificación/descodificación, otros elementos no codificables.

Nosotros reforzamos su idea con la pragmática y el papel primordial que juega el receptor en la creación de meta-representaciones y reescrituras polarizadas Según la Teoría de la Relevancia la comunicación está gobernada por una heurística imperfecta. La comunicación no es un proceso perfecto, es de carácter gradual. Prueba de ello es que cuando Yuste Frías analiza y deconstruye el logotipo de Carrefour ${ }^{10}$ no explica los

\footnotetext{
${ }^{10}$ Pensar en traducir la imagen en publicidad: el sentido de la mirada PLP Pensar La Publicidad, vol. II, n. ${ }^{\circ} 1$ (2008): 141-170. Publicaciones audiovisuales directamente relacionadas con el artículo que han sido editadas antes y después de la publicación del mismo: Para-traducir Carrefour en varios episodios de Zig-Zag que pueden consultarse en http://joseyustefrias.com/ index.php/publicaciones/articulos.html
} 
procesos inferenciales no demostrativos, bien diferentes de los semióticos, por los que llega a la meta-representación de que el referido logotipo pueda interpretarse como una «cruzada contra los precios» o cómo la declinación del mismo en Brasil se muda en reescritura y, en consecuencia, su transformación del «clincher icónico» o gancho visual de los códigos «guerreros» (alabarda medieval) a códigos de naturaleza «lúdica» con intencionalidad publicitaria localizadora (un personaje llamado en portugués «O Precinho» traducido como «precio diminuto»). Con ello crea una meta-representación que constituye lo que podríamos llamar una reviviscencia de la imagen de marca en la que la sorpresa y el humor suponen, en cierta medida, una trasgresión de los códigos por la confusión ocasionada en dos registros de sentido.

En este estudio concreto trataremos de conciliar de forma interactiva la transdisciplinariedad y los tres grandes conceptos de la Teoría de la Relevancia en sus aspectos cognitivos y antropológicos: el de representación mental (mental representation), el de representación pública (public representation) y el de representación cultural (cultural representation).

\section{La valla publicitaria objeto de estudio}

El Discurso Político-Electoral viene a configurarse como un híbrido resultante del discurso político, por un lado, y del discurso publicitario, por el otro. Un interesante ejemplo de esta hibridación lo constituye este reclamo multimodal. En aras de la brevedad en la caracterización rápida de nuestro objeto de estudio, incluimos una imagen de la valla publicitaria (billboard) obtenida de Internet y unas breves informaciones genéricas básicas sobre la misma y que consideramos de interés ${ }^{11}$.

La publicidad exterior está considerada como la forma más arcaica de comunicación de masas que, además de cumplir sus antiguas funciones informativas y comerciales de publicidad racional (reason ads), ha llegado a convertirse, con el tiempo, en un medio de persuasión y de presión ideológica manipuladora, especialmente en EE.UU., nación más permisiva que otras en este aspecto. Debido, fundamentalmente, a que la primera enmienda constitucional (ratificada el 15 de diciembre de 1791) deja patente que «El Congreso no impondrá obstáculos a la libertad de expresión o de la prensa».

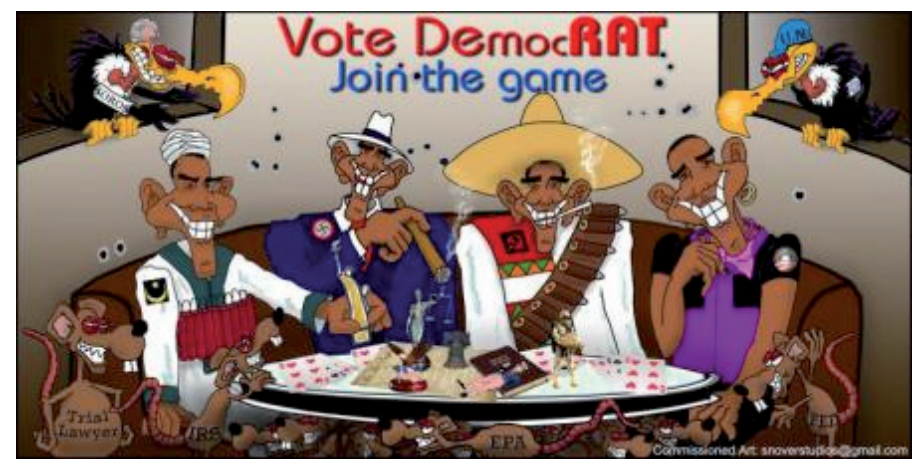

\footnotetext{
${ }^{11}$ Erigida el 19/10/2010 en la denominada Grand Junction (Colorado). Su autor: un artista y dibujante editorial llamado Paul Snover partidario del Tea Party.
} 
Se trata, por tanto, de crear estados de opinión en los miembros de la sociedad convirtiéndose, en consecuencia, en publicidad de alto contenido emocional-sensorial (tickle ads). Martinez Camino (2008) señala:

Esta distinción fue establecida por el publicista David Bernstein $(1974)^{12}$ e introducida en el mundo de la pragmática por Paul Simpson (2001) $)^{13}$. Los anuncios racionales (reason $a d s$ ) se caracterizan por la exposición del producto/logo y las razones por las que debe ser comprado. Los anuncios emocional-sensoriales (tickle ads) son más indirectos: insinúan más que dicen ${ }^{14}$. Es decir, el anuncio prototípicamente emocional-sensorial es aquél que nos hace preguntarnos si eso que estamos viendo es un anuncio.

\section{El modo icónico y visual de los inputs y sus contextos}

Sperber y Wilson (1994) al hablar del estímulo ostensivo como un fenómeno designado para conseguir efectos cognitivos especifican claramente:

Lo que nos interesa aquí son los estímulos utilizados para conseguir efectos cognitivos más bien sutiles: estímulos empleados para hacer una intención informativa mutuamente manifiesta. Los estímulos ostensivos como vamos a denominarlos, tienen que satisfacer dos condiciones: primero, tienen que atraer la atención del oyente, y segundo, tienen que enfocarla hacia las intenciones del emisor.

Desde una perspectiva centrada en el enfoque didáctico que considera de gran importancia la lectura de la imagen publicitaria. Willis García-Talavera (2002) en su artículo «El significante icónico dentro de la estructura semiótica mixta del programa de mano $M-G-M »$, cita a Aparici y García-Matilla (1987) cuándo exponen lo siguiente:

La percepción de una imagen está en estrecha relación con la manera en la que cada individuo puede captar la realidad y, al mismo tiempo, está vinculada con la historia personal, los intereses, el aprendizaje, la motivación. [...] El conocimiento de un objeto no está determinado sólo por las sensaciones visuales, auditivas, olfativas... sino que existe una forma particular (individual/social) de conocerlo. La forma de conectarnos, las emociones hacia un objeto, determinan en buena medida, nuestra carga valorativa hacia el mundo físico. Lo que realiza un observador frente a un objeto es añadirle una asociación significativa a sus sensaciones, que van a depender de la experiencia personal.

Desde un plano puramente visual-descriptivo se está haciendo uso publicitario de determinados estereotipos como una estrategia cognitiva efectiva y se recurre, por el

${ }^{12}$ Este autor ha tratado posteriormente los diferentes formatos de publicidad exterior, entre los que incluye los billboards, en su libro publicado por Paperback en marzo de 1997 titulado: Advertising Outdoors : Watch This Space!

${ }^{13}$ Paul Simpson, de la Queen's Universtity de Belfast, realizó el estudio en 2001. El autor afronta el examen del discurso racional y emocional de la publicidad como una indagación centrada en el proceso y no sólo en el resultado.

${ }^{14}$ Gonzalo Martínez Camino. Diferenciación pragmalingüística de dos tipos de publicidad: publicidad racional vs. publicidad emocional racional. Ma del Mar Rubio Hernández. Universidad de Sevilla. Reseña del libro Publicidad Emocional. Estrategias Creativas de Belén López Vázquez. Madrid, ESIC Editorial, 2007. 
mismo motivo, a otros variados recursos pragmáticos para cargar de intencionalidad a los enunciados. Es un tipo de comunicación en la que el emisor pretende alterar el ambiente cognitivo del receptor de forma indirecta. Este fenómeno es descrito por Tanaka (op.cit.), lo denomina comunicación encubierta (covert communication). Los elementos icónicos de la valla publicitaria parecen gritar, como un todo, este mensaje final (overall effects of the billboard): ¡Obama es un nefasto presidente negro que ni ama a Dios ni a su país y se rodea de ratas dañinas y de buitres codiciosos! Para llegar a este colofón hemos de realizar una lectura más profunda y enjundiosa de la intencionalidad de todos sus contenidos simbólicos. Nuestra aprehensión sobre el presidente y, por ende, la de los candidatos de su partido en este ámbito específico político-electoral se ve afectada por diversos efectos perceptivos. Amorós (2007) señala algunos de ellos: la «percepción selectiva» como prejuicio cognitivo (cognitive bias), se nos quiere obligar a seleccionar sólo aquello que se destaca, ya que el anunciante conoce las creencias, actitudes, preferencias de uso, hábitos y condicionamientos de los receptores afines; el «efecto o error de halo» porque el emisor quiere que en cada representación nos dejemos influir por un solo rasgo personal; el «efecto de contraste», insistiendo en que valoremos a una persona o grupo no de manera aislada sino por comparación con otras u otros; las «defensas perceptuales», estimulando el sentimiento del miedo racial y el rechazo a todo aquello que nos inquieta o atemoriza; la «proyección» atribuyendo características de la propia personalidad del grupo emisor (el extremismo del ingroup) a los demás (outgroup) y, finalmente, con la implacable clasificación en estereotipos se trata de juzgar al otro en función del grupo al que pertenece. Esta es la razón por la que hemos considerado conveniente dividir el mensaje ostensivo-visual del emisor en cuatro apartados que vienen a coincidir, en gran medida, con el concepto semánticocognitivo de metáfora ontológica de G. Lakoff (1995), ya que conocimientos de carácter abstracto son personificados (visión estereotípica de Obama mediante algunos de sus alter egos); zoomorfizados (mediante metáforas deshumanizadoras (dehumanizing metaphors); cosificados (apropiándose de imágenes icónicas para la disensión política (divisive images) y numerizados (valiéndose del maniqueísmo simbólico de las implicaturas numéricas).

\subsection{Visión estereotípica de Obama y algunos de sus alter egos de ficción}

Las caricaturas son presentadas, mediante un discurso visual de ficción, como personificaciones o «segundas identidades» de Barack Obama todas ellas exhiben una enorme y tenebrosa sonrisa. La ropa es otro de los signos de identidad más definidos en la sociedad contemporánea y uno de los aspectos no verbales que ha generado mayor interés en los investigadores en comunicación, en particular, su valor como símbolo de identificación y pertenencia a un grupo social o status determinado. Vamos a describir de manera concisa, las cuatro personalidades que se le asignan en la valla: (1) Obama es un terrorista jihadista (islamophobia): caracterizado con turbante, ropa de martirio, cinto con cartuchos de dinamita y con el logo o emblema del creciente islámico con estrella (islamic crescent with star). Meta-representación: Obama no es cristiano, es musulmán su credo religioso es el Islam. (2) Obama es un matón de 
Chicago $^{15}$ (thugocracy) $^{16}$ : representado como mafioso negro (black cigar-chomping gangster) una recreación de la famosa fotografía de Al Capone masticando un puro. $\mathrm{Su}$ atuendo consta de sombrero, traje y corbata, con el emblema de la cruz gamada o esvástica. Meta-representación: Obama es un nazi y un fascista corrupto. (3) Obama es un bandido mexicano ${ }^{17}$ (xenophobia): ataviado con sombrero mexicano, camisa, manta sobre el hombro, fumando y portando una canana repleta de munición (ammo belt) con la insignia del partido comunista (the hammer-and-sickle). Meta-representación: Obama es un bandido comunista partidario de abrir las fronteras a la inmigración. (4) Obama es un extravagente homosexual (homophobia): representado con un pendiente de oro en su oreja, un vestido púrpura o morado y un corpiño negro (top) con el logo de Obama "declinado" como LGBT ${ }^{18}$ por Obama (Obama's rainbow logo gay). Metarepresentación: Obama es un decidido defensor de los derechos de gays, lesbianas y transexuales.

Hemos recalcado en cada apartado las formas inglesas más comunes de intolerancia (bigotry), asociadas a este discurso violento (hate speech). Como muestras de patrones de fanatismo podrían ser analizadas desde un punto de vista filosófico-humorístico (teorías de la superioridad, de la descarga y de la incongruencia); desde una perspectiva antropológica examinando el papel desempeñado por la alteridad (the others) o desde el campo sociológico en el que resultaría de especial interés el análisis interaccionista estratégico del sociólogo Erving Goffman (1998) que al estudiar los ritos de interacción hace una interesante aportación sobre la utilización política del estigma ${ }^{19}$. El juicio moral -la tendencia a culpar al otro de lo que le sucede- y el temor a la peligrosidad de un negro como presidente son fuentes importantes de la discriminación. El uso de estas identidades políticas negativas, que pertenecen al mundo de lo simbólico, se esfuerzan por crear también una presión concreta de rechazo en torno a la vida de los grupos más

${ }^{15}$ In Gangster Government: Barack Obama and the New Washington Thugocracy, David Freddoso, bestselling author of The Case Against Barack Obama. exposes the real truth of Obama's background in Chicago's bare-knuckle politics and White House that approaches Chicago levels of skullduggery and corruption. http://www.conservativebookclub.com/products/BookPage. asp?prod_cd $=\mathrm{C} 7707$

${ }^{16}$ Thugocracy: rule of a country or state by a group of thugs (gobernar un país o un Estado por un grupo de matones). Thugs use intimidation. A liberal application of "Do this or I'll do that," as a means of forcing innocent people, seen merely as sheep to be fleeced, into doing what they want. The examples of the Obama Administration's thuggishness abound and are as close as the headlines. http://www.canadafreepress.com/index.php/article/27561

${ }^{17}$ El presidente Obama, que llegó a la Casa Blanca con dos tercios del voto hispano y la promesa incumplida de una reforma de inmigración para el 2009, también ha criticado la polémica legislación de Arizona contra los "sin papeles". http://www.abc.es/20100701/internacional/ obama-inmigracion-201007011806.html

18 LGTB: son las siglas que designan colectivamente a las lesbianas, los gays, los bisexuales y las personas transgénero.

${ }^{19}$ El estigma puede definirse como el efecto negativo que una marca o una etiqueta produce en un grupo, tal como una minoría étnica, religiosa o pacientes con ciertas enfermedades entre las que se destacan el sida y la enfermedad mental. El estigma incluye tres elementos: un problema de conocimiento (ignorancia), un problema de actitud (prejuicio) y una conducta (discriminación). 
vulnerable ${ }^{20}$ y en señalar a los otros como enemigos internos o externos. El peligro de propugnar este aprendizaje vicario y sus efectos miméticos reside en que, muchas veces, la identidad negativa trasciende el plano de la comunicación para ingresar en el de la acción, lo que puede dar lugar a muestras de violencia (racist backlash), producto de la intolerancia inherente a los procesos estigmatizantes. Pensemos por un momento, a título de ejemplo, en el «proyecto Minuteman» o «vigilantes» fronterizos en Arizona.

\subsection{Metáforas zoomórficas deshumanizadoras}

Cuando otorgamos a una persona o a una institución atributos de animales con la finalidad de darle una apariencia turbadora y alarmante nos sumergimos de lleno en el proceso cognitivo conocido como humor grotesco que implica, en gran medida, una agresión o un ataque hacia las personas e instituciones aludidas.

Si en el apartado anterior se demonizaba al presidente acusándole de variadas formas de criminalidad política (terrorista, mafioso, bandido y marginal), en esta segunda sección podemos observar el uso político-propagandístico de la animalización de los otros (outgroups) que conlleva una interpretación culturalista de su uso basada en los juegos de intereses políticos. Según Paul Snover, el autor de la valla, se trata de representar gráficamente las influencias que recibe el gobierno del presidente Obama. Dos tipos de animales aparecen en ella: ratas (animalización de instituciones consideradas despreciables por sus malas artes y por el daño que procuran a otros) y buitres (animalización representando la avaricia y la fascinación por el poder, la ganancia y el lucro de personas e instituciones). Seis ratas se exhiben en la valla mostrando sonrientes sus afilados dientes, cuatro de ellas, consideradas por el emisor como las más dañinas, están perfectamente etiquetadas y los dos buitres poseen también las suyas.

Estas etiquetas, mediante el anclaje tanto icónico como verbal, contribuyen eficazmente a que el receptor obtenga con el menor esfuerzo posible la relevancia óptima. Rata 1: los abogados litigantes (trial lawyers) fueron el mayor contribuyente al Partido Demócrata en el ciclo de 2008, recaudando para la campaña 47 millones de dólares. Rata 2: IRS (The Internal Revenue Service), es la agencia federal del Gobierno de los Estados Unidos, encargada de la recaudación fiscal y del cumplimiento de las leyes tributarias. El ideario político sobre los impuestos del Tea Party queda resumido en este acróstico: Taxed/Enough/Already. Rata 3: EPA (Environmental Protection Agency) ${ }^{21}$ instaurada por Richard Nixon, es una agencia del gobierno federal de Estados

\footnotetext{
${ }^{20}$ Prostitutas, travestís, homosexuales, negros, inmigrantes, drogadictos, dementes, discapacitados, etc.

21 Jimmy Carter ex presidente y Premio Nobel, hizo unas declaraciones (31/10/2010) en $\mathrm{CNN}$ en las que afirmo que los famosos Tea Parties fueron financiados por las grandes compañías norteamericanas que deseaban derrotar los reglamentos ecológicos e impedir las leyes regulatorias que el presidente Obama ha estado proponiendo y que han sido aprobadas por el Congreso. http://politicalticker.blogs.cnn.com/2010/10/31/carter-tea-party-forbearerselected-me/ There has been a vociferous debate in both the House and Senate over whether the Environmental Protection Agency should have the power to regulate greenhouse gas emissions. http://www.prensalibre.cr/pl/comentarios/35360-lo-antisignificativo-lo-protectivo-y-locatolico.html
} 
Unidos encargada de proteger la salud humana y el medio ambiente. La derecha conservadora la considera dañina porque al propugnar las energías renovables puede ocasionar daños irreparables a los lobbies petroleros y a los de energía nuclear. Rata 4: FED (Federal Reserve System) es una entidad público/privada encargada de guardar todos los fondos de los bancos del sistema bancario norteamericano. El Tea Party es un fuerte crítico de su «excesivo poder» y quiere reforzar su supervisión. Buitre 1: George Soros $^{22}$ fue uno de los mayores contribuyentes a la campaña presidencial de Obama. La etiqueta lo marca como $« \$ o r o \$ 》$ quien, al parecer, consiguió su fortuna gracias a generar terremotos bursátiles -de ahí el uso del símbolo del dólar por la letra S- . Buitre 2: Naciones Unidas, este buitre aparece con una gorra azul con la siglas UN (United Nations) y con el emblema corporativo de ese organismo sobre su ala izquierda (su financiación proviene de contribuciones voluntarias de los Estados miembros por lo que, según los conservadores, no debe inmiscuirse en debates internos de EE.UU.).

\subsection{La apropiación de imágenes icónicas para la disensión política como parte de la ideología nacionalista identitaria y excluyente}

Las cuatro identidades señaladas se encuentran sentadas ante una mesa de póker y apuestan o ponen en juego los emblemas más identitarios y emocionales de la cultura política estadounidense. Con esta alegoría, se está recurriendo a la apropiación de esos símbolos por parte de grupos nacionalistas minoritarios. Estos ideogramas de gran importancia simbólica y emotiva, rebasan la mentalidad "patriotera» (jingoism: we are the real patriots) porque esos iconos pertenecen al acerbo cultural de la totalidad de los ciudadanos de una nación. Desde la perspectiva de una concepción «identitaria y excluyente» el «yo nacional» exige una ineludible homogeneidad cultural, étnica y religiosa que pruebe su unicidad y exclusividad en relación a los otros habitantes y frente a otras naciones.

A continuación señalamos las ocho representaciones cuya presencia hemos identificado sobre la mesa de póker, a saber: la estatua de la Libertad, el Acta de Declaración de Independencia, la estatuilla de la justicia, el águila calva americana, la campana de la Libertad, el Tío Sam, la Biblia y un soldadito de plomo. La estatua de la libertad (liberty enlightening the world) o «la libertad iluminando el mundo» no es solo un monumento importante en la ciudad de Nueva York, es también un símbolo en todo el país que representa, en un plano más general, la libertad y la emancipación con respecto a la opresión. El acta de la declaración de independencia (The 1776 Declaration of Independence) de las trece colonias inglesas en Norteamérica (1776) dio origen a los EE.UU. Este documento es uno de los principales instrumentos de inspiración de la conciencia estadounidense. La estatuilla de la justicia con una balanza (blindfolded Justice) es la personificación alegórica de la fuerza moral del sistema judicial. La venda en los ojos representa la objetividad que debe guiarlo. Los nueve jueces del Supremo, una vez nombrados por el presidente, cuentan con ese cargo de por vida y disponen de un inmenso poder. El águila calva americana (The Bald Eagle) es el símbolo nacional

\footnotetext{
${ }^{22}$ George Soros es considerado una de las 'maquinarias inversoras' más influyentes del mundo. Describe sus “principios” en el libro La Alquimia de las Finanzas, en el cual dice «lo que crean los especuladores será más importante que la realidad de la economía».
} 
de EE.UU. Se puede encontrar en el Gran Sello de los Estados Unidos, en el sello presidencial, en la mayoría de las monedas, papel moneda y en multitud de timbres. La campana de la libertad (Liberty Bell) fue usada como un icono internacional de libertad ${ }^{23}$. Con su toque más famoso, el 8 de julio de 1776 convocó a los ciudadanos de Filadelfia para la lectura de la Declaración de Independencia. Anteriormente había sido tocada para anunciar la apertura del Primer Congreso Continental en 1774 y después de la Batalla de Lexington y Concord en 1775. El tio Sam (Uncle Sam) es la personificación nacional de Estados Unidos y, específicamente, del gobierno estadounidense. La Biblia $^{24}$ (Holy Bible) es más que un símbolo para el movimiento ultraconservador Tea Party que se muestra extremista en el aspecto religioso y difunde la ortodoxia cristiana. La organización CWA (Concerned Women for America) pretende aplicar los principios bíblicos a la política actual y, finalmente, la representación del soldado americano (toy soldier) nos incita a inferir que Obama, como comandante supremo, tiene en sus manos las vidas de las tropas estadounidenses desplegadas por todo el mundo como si de soldaditos de juguete se trataran.

\subsection{El maniqueísmo simbólico de las implicaturas numéricas}

Un número simbólico es todo aquel que no denota una cantidad, sino que pretende revelarnos una idea, un mensaje distinto (implicatura). En la Biblia se cita el número 666 como la marca de la Bestia, relacionado con Satanás o con el Anticristo. La asociación del mal a una voluntad personal lleva al psicólogo francés L. Ferry a examinar la hipótesis psicologista, según la cual el mal nace en un psiquismo patológico. Todas las personificaciones de Obama tienen delante de sí tres cartas con el 6 de corazones agrupadas en bloques de tres (666), la marca de la bestia. El maniqueísmo político dirige a la masa que profesa una ideología concreta en contra de la rival mediante una falacia, muy usada en entornos políticos, el Argumentum ad populum, también llamado sofisma populista consistente en demonizar la ideología contraria y hacer perfecta la propia, cayendo muchas veces en la contradicción. Bello Reguera (2008) sostiene que:

La demonización del otro -la asimilación del otro a la figura del diablo, o su identificación con esa figura- es un instrumento político de primer orden: de ella se sigue de forma inmediata y directa la necesidad de su destrucción en nombre del bien/Dios, representado por el demonizador de turno.

La doctrina del «eje del mal» promovida por el presidente George W. Bush o la demonización de Estados Unidos propugnada por Bin Laden son ejemplos opuestos y palmarios.

\footnotetext{
${ }^{23}$ La campana tiene grabado en su interior la siguiente cita bíblica: «Proclaim liberty throughout all the Land unto all the inhabitants thereof». Leviticus 25:10.

${ }^{24}$ Los estados que conforman el Cinturón bíblico también son conocidos por discriminar a los ateos para ejercer cargos públicos. Arkansas, Carolina del Norte y del Sur, Maryland, Pensilvania, Tennessee y Texas tienen leyes específicas para impedir que los ateos accedan a cargos públicos.
} 


\section{El módulo lingüístico de los inputs y sus contextos}

En general, para calibrar el valor de los inputs verbales de esta valla publicitaria, debemos llevar a cabo una serie de tareas: en páginas anteriores ha quedado patente que las etiquetas colocadas sobre las personas y los animales nos ayudan a identificar lo que ambos encarnan. Hemos valorado el papel que representan los números de las cartas y la función que juega esa representación para la comprensión del mensaje. Nos resta la tarea de apreciar el papel de las dos frases del eslogan y ver si el mensaje final queda claro a pesar de poseer una cierta ambigüedad semántica $\mathrm{y}$, finalmente, deberemos evaluar hasta qué punto las palabras y las frases contribuyen a explicar los símbolos. Herrero Cecilia (1997) nos ilustra sobre el papel desempeñado por los inputs verbales en el mensaje publicitario cuando señala.

La fórmula del eslogan habrá sido cuidadosamente estudiada y seleccionada en función del público al cual va destinada y de los efectos comunicativos perseguidos por el Emisor/ Productor del enunciado. En realidad, cualquier tipo de enunciado podría convertirse en un buen eslogan si logra hacer reaccionar al Destinatario en la línea deseada por el Sujeto productor del mensaje.

\subsection{La función de relevo (complentariedad) y/o anclaje del eslogan}

Para que el juego de la ambigüedad semántica funcione hay que tener en cuenta las relaciones que el eslogan establece con los otros elementos semióticos inscritos en el texto del anuncio. Herrero Cecilia (1997: 338) nos aclara:

La clave de la ambigüedad o de la ambivalencia reside en saber interpretar esas relaciones. El Sujeto creador del anuncio debe recurrir entonces a una serie de estímulos ostensivos (ciertas figuras de estilo, el choque entre dos o más isotopías, el valor semiótico de la imagen, etc.) que permitirán la cooperación interpretativa del Destinatario dando lugar a determinadas inferencias y a la percepción de ciertas connotaciones que puedan resultar más o menos sugestivas, ingeniosas o evocadoras. Estos resultados comunicativos corresponden a lo que Sperber y Wilson (1989) llaman efectos contextuales pertinentes. La pertinencia comunicativa depende del estilo específico de cada enunciado elaborado en un contexto determinado de interacción entre los interlocutores. Sperber y Wilson (1989: 326-329) afirman que el juego del estilo nos permite percibir la idea que el Locutor se hace de las capacidades cognitivas del Interlocutor, y del grado de complicidad que puede existir entre ambos, lo cual repercutirá en la manera de organizar lo explícito en el enunciado y lo que se va a dejar implícito.

La duplicidad enunciativa mediante el juego de la ambigüedad semántica se produce por un choque o contraste ingenioso entre dos isotopías (niveles de sentido). Por un lado aparece una isotopía de contexto (RAT, operando de forma alusiva) y por otro, el mismo enunciado sirve para crear la isotopía del texto ${ }^{25}$. El juego de la ambivalencia se

${ }^{25}$ The United States Democratic Party. Usually characterized by beliefs such as: personal privacy rights, including legalized abortion and gay marriage/ protection of civil liberties/ protection of the environment/ multilateral foreign policy/ extensive government services, such as health care, education, and welfare/ tax system that causes the rich to pay more taxes to pay for government services. 
refuerza con las maniobras de las semejanzas rítmicas, prosódicas, léxicas y tipográficas. El tono del enunciador es, fundamentalmente, agresivo, persuasivo e irónico pues su proposición establece una oposición chocante con algo que le resulta más familiar al Destinatario (votar a un partido). La violencia de la caricatura reposa igualmente sobre las tres letras mayúsculas que forman la palabra «RAT», direccionando completamente el sentido de las imágenes. Se trata de una estrategia de focalización pragmática del discurso mediante el empleo de dos recursos combinados: la utilización de los colores rojo (republicano) y azul (demócrata) - colores que representan, combinados, los de la bandera estadounidense- y el uso específico de las letras mayúsculas. Sperber y Wilson (op. cit.) dejan patente que: "utilizamos las mayúsculas para representar tanto el énfasis focal (oracional y nuclear) como el énfasis contrastivo". El lema o eslogan de la valla (billboard tagline):

\section{Vote DemocRAT/ Join he game}

López Folgado (2010) argumenta: «Un simple juego de palabras, o desvío inesperado en la información, hace que el oyente se pierda en conjeturas sobre las posibles intenciones comunicativas del emisor». La incongruencia, es decir, la falta de adecuación o el efecto sorpresa producido por la diferencia grafico-tipográfica entre «Democrat»y «DemocRAT» revela la base o la fórmula lingüística que produce la perlocución o efecto causado en el lector por la semejanza fónica entre «democrat» y «democRAT». Se puede producir un efecto de acento secundario y de los grupos fónicos en la interpretación del enunciado, observamos como la letra «c» que los divide ha reducido ligeramente su tamaño. El color rojo de la frase lo podemos interpretar como un grito republicano. La disonancia cognitiva es un concepto típico de la psicología social. Todos defendemos nuestras opiniones con razones, o defendemos nuestras razones con opiniones. La segunda frase del eslogan, «Join the game» en color azul, parece estar escrita por los demócratas que incitan a unirse al juego de póker a todos aquéllos que de una u otra manera simpaticen con ellos pero la ambigüedad semántica del enunciado nos impulsa a reparar, también, en que si lo hacen serán considerados por el ultranacionalismo como antipatriotas, anticristianos, como ratas despreciables y dañinas o como buitres avariciosos y llenos de codicia. Se está utilizando el recurso al Argumentum ad verecundiam o falacia de la autoridad moral del emisor al que se supone virtuoso.

\section{El papel de las implicaturas y de las metáforas visuales}

En multitud de ocasiones captamos los mensajes a través de metáforas porque determinados conceptos son abstractos, vastos, incorpóreos y no los podemos percibir de forma inmediata ni de una manera tangible o precisa. Para hablar de ellos, para emplearlos en mensajes publicitarios, debemos metaforizarlos y de esta manera facilitaremos el proceso de comprensión del receptor. La historia de EE.UU. está repleta de destacados enemigos públicos que han servido para catalizar tanto el miedo como la energía de la nación. Si las metáforas que se nos ofrecen en la valla publicitaria tienen la cualidad de ser visuales entonces podemos establecer esa igualdad general 
que dice que "conocer es ver», a través de ellas, una sucesión de enemigos hostiles. Tanaka (1994) apuntaba desde el prisma de la Teoría de la Relevancia: «the metaphor makes the hearer see some resemblance between things where she may not have seen it befote» y más recientemente Diaz Pérez (1999), asumiendo el texto de Tanaka, señalaba lo siguiente:

Según la cantidad y fuerza de las implicaturas extraídas, Sperber y Wilson distinguen entre metáforas estereotipadas o convencionales y metáforas creativas. En el caso de aquéllas, el receptor recuperará un número restringido de implicaturas fuertes, mientras que en el de éstas, se verá impulsado a recuperar un amplio espectro de implicaturas débiles. Por tanto, cuánto más amplia sea la gama de implicaturas y más débiles sean éstas, mayor será el grado de creatividad de la metáfora y mayor la responsabilidad del oyente a la hora de derivar las implicaturas.

Denominamos implicatura contextual al tipo más importante de efecto cognitivo, a una conclusión que se deduce del input y del contexto en conjunto, nunca de alguno de los dos por separado. Señalaremos en primer lugar dos implicaturas básicas (mutual manifestness) que se desprenden de la valla que, como escenario está apelando al más inmediato background knowledge del receptor y, pueden ser consideradas por tanto, como auténticas explicaturas debido al nivel de certeza que representan para el receptor (entorno cognitivo inicial): (a) Obama milita en el Partido Demócrata. (Cierto). De todos es conocido que Barack Obama hizo historia al ganar la nominación demócrata a la Casa Blanca a su rival Hillary Clinton, (b) Obama es el primer presidente negro de EE.UU. (Cierto). El senador demócrata por Illinois se convirtió en el primer presidente negro de la historia de EEUU con más de 62 millones de votos.

A pesar del valor polisémico de las imágenes defendido por el autor francés R. Barthes podemos obtener como más relevantes -sin olvidar que la relevancia es una cuestión de grados-, las siguientes implicaturas contextuales de las metáforas visuales estereotipadas de la valla publicitaria que constituyen nuestra para-traducción metarepresentativa: (1) Obama es un terrorista jihadista islámico. (implicatura fuerte). Desde que ingresó en la Casa Blanca Barack Obama dejó muy en claro que quería un cambio en la relación de EE.UU. con el mundo musulmán. En su discurso de toma de posesión habló de un nuevo enfoque basado en el interés y el respeto mutuo. El antagonismo del Tea Party, reflejado en la caricatura, nos remite a sus acusaciones al Islam de conspirar para dominar el país a través de la ley islámica o Sharia; a las acciones del movimiento ultraconservador contra la construcción de nuevas mezquitas y centros islámicos; a la identificación de musulmán con un enemigo terrorista y, por ende, al llamamiento que Osama Bin Laden ${ }^{26}$ hizo a todos los musulmanes en 1998 para que participasen en una «guerra santa» contra las «satánicas tropas de los Estados Unidos y los demoníacos aliados que las respaldan».

${ }^{26}$ Como queriendo liberarse del estigma de jihadista, Barack Obama dio autorización a un comando de las tropas especiales estadounidenses (Navy Seals) para una misión especial en Pakistán. Como consecuencia de la misma Osama Bin Laden fue abatido en un espectacular asalto a la residencia que ocupaba en una pequeña localidad de Pakistán el día 1 de mayo del 2011. 
Estableciendo por asociación (flaw of argumentation) un grado emotivo de cooperación necesaria con los atentados del 11 de Septiembre, con el terrorismo internacional y con la defensa a ultranza de los intereses palestinos frente a una tibieza imperdonable en el apoyo a Israel. (2) Obama es un gangster como Al Capone (implicatura fuerte). El estereotipo del mafioso surge en los tiempos de la Ley Seca durante la cual el gangsterismo -especialmente la figura de Al Capone en Chicago- se erigió en paradigma del malhechor y de amenaza para la sociedad. La Congresista republicana Michele Bachmann consiguió de la multitud «rugidos» de aprobación cuando, en un mitin celebrado en Washington ${ }^{27}$, acusó al presidente Barak Obama y a los demócratas del Congreso de tratar de asumir el control de la sanidad, de la energía, de los servicios financieros y de otros amplios sectores de la economía. La idea subyacente es que el gangsterismo del gobierno Obama está haciendo presa en sus negocios, los está extorsionando obligándoles a pagar más impuestos para sobornar a las masas. Sus frases fueron vehementes: ;estamos hartos de ellos, estamos hartos de este gobierno mafioso! (We're on to them. We're on to this gangster government); ;no vamos a consentir que se salgan con la suya! (And we are not going to let them have their way), jtenemos que mandar a estos cerdos a casa! (I say it's time for these little piggies to go home). El libro de David Freddoso, periodista del Washington Examiner, titulado «Gangster Government: Barack Obama and the New Washington Thugocracy» que ha sido puesto a la venta en abril del 2011 viene a reforzar, medio año después, esta imagen estereotipada que nos ofrece la valla publicitaria. (3) Obama es un bandido mexicano. (implicatura fuerte).

El presidente Barack Obama estuvo recibiendo la presión de la población hispana, que con su voto le ayudó a llegar a la presidencia, para que propusiera cambios en la política migratoria. Obama planteó una propuesta de ley para legalizar a los jóvenes indocumentados: «The Dream Act» pero el Senado ha rechazado hasta el momento su aprobación. Este proyecto permitiría a los hijos de inmigrantes poder estudiar, ser parte de las fuerzas armadas, obtener una residencia temporal y finalmente con el paso de los años conseguir la ciudadanía, como parte de la reforma del sistema de inmigración. Barack Obama llegó a manifestar ante el presidente de México, Felipe Calderón, que la ley aprobada en Arizona contra la inmigración ilegal podía tener consecuencias discriminatorias contra toda la población de origen hispano. La discrepancia opositora conservadora queda reflejada en esta visión estereotipada de la caricatura que ha sido alimentada durante años por el cine estadounidense. En este sentido Velázques García (2008) comenta:

Uno de los estereotipos más reconocidos sobre el mexicano (latino) dentro de las películas estadounidenses es el bandido. (...) Su comportamiento corresponde a lo que Klahn $(1994)^{28}$ propone sobre la otredad del mexicano (latino): vicioso, cruel, traicionero

${ }^{27}$ The United States Democratic Party. Usually characterized by beliefs such as: personal privacy rights, including legalized abortion and gay marriage/ protection of civil liberties/ protection of the environment/ multilateral foreign policy/ extensive government services, such as health care, education, and welfare/ tax system that causes the rich to pay more taxes to pay for government services.

${ }^{28}$ KLAHN, Norma (1994): “La Frontera imaginada inventada o la geopolítica de la literatura a la 
y deshonesto. (...) Tanto estas cintas como en general los western se caracterizan por su racismo no sólo hacia los mexicanos sino también hacia los afroamericanos, indios nativos de Norteamérica y asiáticos $\left(\right.$ Quart,1984) ${ }^{29}$. Estas películas retomaron las imágenes negativas sobre el mexicano como un elemento ideal de contraste frente al héroe americano.

Las metáforas forman parte del lenguaje aproximativo (loose talk). Glenn Beck, ha llegado a asegurar que la inmigración de México causará «el colapso de Estados Unidos», y que los inmigrantes mexicanos son «pobres, criminales o terroristas» por lo que se deberían pedir compensaciones por esto: should Mexico Compensate U.S. for Cost of Illegals? Lou Dobbs, uno de los más importantes presentadores de noticias y comentaristas de la cadena de televisión CNN, no se ruborizaba al declarar: «La invasión de extranjeros ilegales es una amenaza para la salud de muchos estadounidenses". Tom Tancredo, conocido anti-inmigracionista, aseguraba que Obama llegó al poder porque «en este país no se necesita examen cívico y de alfabetismo para votar» (nostalgia por la época de la segregación cuando se impedía el voto a los negros). Por desgracia este tema sigue aún hoy en candelero. Mónica Novoa ${ }^{30}$ manifestaba en Colorlines. com, USA. "Immigrants are dehumanized every day in the nation's discourse with the slur «illegals». It should be no surprise that they are treated with inhuman, out-ofproportion violence from law enforcement as well». (4) Obama apoya el matrimonio gay (implicatura fuerte). Obama expresó su apoyo a la causa en pro de los derechos de la comunidad homosexual en su campaña presidencial. Prometió, entre otras medidas, eliminar la norma «Don't ask, don't tell $\rangle^{31}$, derogar la ley federal de defensa del matrimonio y establecer acciones concretas para eliminar la discriminación laboral basada en la orientación sexual. En contraposición, la caricatura refleja la retórica anti-gay cargada de intolerancia y de prejuicios del Tea Party. Para ellos, el gobierno de Obama y el movimiento LGBT constituyen un auténtico maridaje. Christine O'Donnell, candidata por Delaware, aseguraba que «los gays crearon el sida». Su declaración tratando de demonizar a este colectivo resulta especialmente llamativa. En las manifestaciones del Tea Party aparecen pancartas como esta: «Down with sodomy!

nada”, en Ma. Esther Schumacher (ed.). Mitos en las relaciones México-Estados Unidos. Fondo de Cultura Económica (primera versión del mismo trabajo: "Writing the Border: the languages and limits of representation". Travesía: Journal of Latin American Cultural Studies, vol.3, núm $1-2)$.

${ }^{29}$ Quart, Leonard y Auster, Albert (1984): American Films and society since 1945. Londres. McMillan Publisher Ltd.

30 April 21, 2011. The Casual Violence That Dehumanizing Language Breeds. http://colorlines.com/archives/2011/04/drop_the_i- word_the_casual_violence_that_dehumanizing_language breeds.html

${ }^{31}$ Don't ask, don't tell : "No pregunte, no diga" o "prohibido preguntar, prohibido decir". Es la expresión con la que se conoce popularmente la política sobre homosexualidad de las fuerzas armadas de los Estados Unidos desde 1993 hasta diciembre de 2010, que establecía la legislación federal (10 U.S.C. § 654) y que fue revocada por la Cámara de Representantes el 16 de diciembre de 2010 y por el Senado de Estados Unidos el 18 de diciembre de 2010. Fue derogada por el presidente, Barack Obama, el 22 de diciembre de ese mismo año. Véase http://es.wikipedia. org/wiki/Don $\% 27 t$ task,_don $\% 27 t$ t tell 
Up with Tea Bagging! ». (5) Obama ha cometido el error de dejarse influir por ratas dañinas y buitres codiciosos (implicatura menos fuerte). He aquí un breve apunte sobre estas ratas y esos buitres: a) según el Tea Party, la única gente que no está de acuerdo en reformar el sistema de demandas sobre negligencia médica es un puñado de poderosos abogados litigantes, y un puñado de políticos que reciben un gran apoyo económico de esos abogados (rata 1); b) el movimiento conservador, en su enconada lucha contra los impuestos federales, ataca sin miramiento a la agencia encargada de la recaudación fiscal y del cumplimiento de las leyes tributarias (IRS) -rata 2-; c) lanza sin recato la denominada ofensiva "anti-verde" contra la Agencia de Protección Ambiental (EPA) -rata 3- y, en consecuencia, contra las contadísimas medidas de prevención contra el cambio climático anunciadas por el presidente Obama y d) no sólo manifiestan su desconfianza hacia una de las instituciones económicas más importantes del planeta: la todopoderosa Reserva Federal (FED) -rata 4- sino que un importante porcentaje de «teabaggers» aboga directamente por su desaparición.

Como ya hemos podido advertir, en páginas anteriores, uno de los buitres representa a George Soros que es un especulador financiero, inversionista y activista político, de origen judío nacido en Hungría pero de nacionalidad estadounidense. En su momento se pronunció en contra de la reelección del presidente George Bush y declaró su apoyo al actual presidente de los Estados Unidos, Barack Obama, desde los albores de su candidatura. Los conservadores del Tea Party consideran al presidente Obama como una de sus marionetas, de ahí que Soros reciba el apodo de «puppetmaster», un término cargado de connotaciones que se remonta a la propaganda goebbeliana de la Alemania nazi. El Tea Party acusa a las Naciones Unidas, el otro buitre, de urdir complots o conspiraciones para limitar las libertades de los estadounidenses como el derecho a llevar armas. Sus candidatos en estos comicios, proponían la retirada de EE.UU. de las Naciones Unidas. Consideran que hay muchas cosas que el Congreso estadounidense puede hacer para controlar las contribuciones al sistema de la ONU y reforzar sus intereses. (6) Obama está jugándose al póker «the American way of life» representado por los más sagrados símbolos del país (implicatura menos fuerte). La escena de la mesa de juego viene a recordarnos el cuadro denominado «True Blues» \& «Grand Ol' Gang» de Andy Thomas (pintor norteamericano especializado en la cultura e historia de su país). Alrededor de una mesa de póker ${ }^{32}$, se ha decidido el destino de mucha gente. De todos es conocido que los juegos de azar se vuelven adictivos y en muchísimos casos conducen a otros malos hábitos y a prácticas destructivas.

Con esta comparación metafórica, se está haciendo clara referencia al intento de aniquilación, por parte del gobierno, de un espíritu nacionalista conservador que pretende adherirse a los principios de la vida, de la libertad y de la búsqueda de la felicidad y que mantiene estrechos vínculos con la noción del excepcionalismo americano y del sueño americano que vienen a ser los ideales de la denominada América Profunda (WASP - White Anglo-Saxon Protestant-). Por esta razón construyen una alegoría política a través del ardid conocido como «patchwork quilt fallacy». David Casacubierta (1999)

${ }^{32}$ El póker es un juego que ha atraído a muchos presidentes norteamericanos, entre ellos George Washington, Abraham Lincoln, Harry Truman, Roosevelt, Lyndon Johnson y Richard Nixon que tras la guerra se hizo famoso entre sus compañeros de filas por su habilidad con las cartas, específicamente jugando al póquer. 
la describe de esta manera:

In this fallacy, the person arguing presents unconnected facts, taken from several fiels and presents a rather implauisble hipótesis according to which, if conect, all those unconnected facts would be explained. Of course, the main point is that there is no real need to explain the unconnected facts, so the evidence does not help to take the hypothesis seriously.

Nuestra interpretación es que los diferentes símbolos que aparecen como bazas en juego sobre la mesa de póker constituyen un totum revolutum argumental que trata de representar desde el punto de vista conservador y opositor los peligrosos envites de Barack Obama: (a) un musulmán apuesta la Estatua de la Libertad mostrando con ello que uno de los objetivos de Obama consiste en eliminar las libertades estadounidenses para implantar la ley islámica (sharia) que prescribe la lapidación de las adúlteras o que corta la mano a los ladrones. Es digno de destacar que tras el éxito parcial del Tea Party en estos comicios, los habitantes de Oklahoma realizaron una consulta formal y votaron en masa para mantener la sharia lejos de sus vidas. (b) los partidarios del Tea Party sostienen que no debe existir nada que no esté mencionado en la Constitución de manera expresa. El movimiento conservador entiende que la excesiva intervención del Estado no solamente limita las libertades individuales sino que ahoga la creatividad emprendedora y la creación de empleo. (c) Barack Obama se ha atrevido a nombrar a Sonia Sotomayor ${ }^{33}$, una hispana, como miembro del Tribunal Supremo. Los magistrados de este alto tribunal deben ser auténticos estadounidenses para defender, por encima de todo, los valores constitucionales, y no deben ser nombrados jueces «outsiders" porque hayan mostrado su lealtad al Poder Ejecutivo, por eso apuesta la estatuilla de la Justicia. (d) ¿Cómo es posible que un negro esté presidiendo a la gran nación del águila calva? de ahí la apropiación interesada del símbolo. (e) La Campana de la Libertad volverá a sonar para señalar el batacazo de Obama en estas elecciones de mitad de mandato. (f) El Tío Sam no representa al gobierno de Obama porque éste no defiende valores estadounidenses tan preciados como la responsabilidad personal y la virtud de trabajar. El gobierno federal esta creciendo de tal manera que: «the more government grows, the less freedom we have because we're the ones paying for it». (g) Los conservadores han llegado a utilizar camisetas con la frase atribuida a George Washington «it is impossible to righty govern a nation without God and the Bible». Otras llevan el lema: «One nation under God» o ¡Más religión y menos Estado! Son los poderosos mensajes del llamado «cinturón bíblico». Todos estos mensajes nos hacen recapacitar sobre el rol desempeñado por la religión como fuente de poder político. (h) El comandante supremo de nuestras tropas, un antiamericano, tiene en sus manos la vida de nuestros soldados en las guerras de Irak, de Afganistán y en las bases estadounidenses repartidas por todo el globo. No olvidemos que el Tea Party reclamaba en su programa la retirada de todas las tropas de Estados Unidos en otros países por esta razón se ironiza con el juguete del soldado.

${ }^{33}$ El 26 de mayo del 2009 el presidente Barack Obama la nominó para el cargo de Juez Asociada del Tribunal Supremo. El 6 de agosto de 2009, el nombramiento de Sotomayor fue sometido a votación en el pleno del Senado y confirmado por 68 votos a favor y 31 en contra. 
Esta forma de actuación argumentativa es lo que se ha venido en llamar «antífrasis» o la inversión semántica de la derecha (right-wing semantic inversion). Cuando un argumento no se basa en la autoridad moral -recordemos la política neoconservadora de George W. Bush-, el recurso al tu quoque ${ }^{34}$ suele ser falaz. David Casacubierta y otros (1999) intenta en su artículo aplicar el modelo de la Relevancia a las falacias que se producen en las teorías de la conspiración. Allí afirma:

"Ad hominem" and "patchwork quilt" fallacies are common place in conspiracy theory arguments. We believe that both fallacies can be explained and analysed using the theoretical framework proposed by relevance theory, because they entail the incorrect use of context and contextual efforts.

Todo lo antedicho puede ser aplicado a cuánto hemos expuesto y a las metáforas creativas representadas por los diferentes emblemas que Obama lleva adheridos en sus ropas en las cuatro personificaciones. Estas insignias constituyen una auténtica teoría de la conspiración, a saber: a) emblema del creciente islámico. Obama es de religión musulmana (Implicatura débil). El portavoz adjunto de la Casa Blanca Bill Burton tuvo que salir en defensa de la "cristiandad" del presidente en respuesta a las encuestas que demostraban que el $34 \%$ de los norteamericanos no le identifican como "cristiano" y el $40 \%$ no está seguro, b) La cruz gamada o esvástica: Obama es un nacional socialista (Implicatura débil), c) emblema del partido comunista: Obama es un socialista marxista (Implicatura débil). Nosotros nos preguntamos: ¿qué otras metáforas pueden representar con más fuerza la condición personal de cualquier ciudadano de ser un antiestadounidense que considerarlo un nazi, un comunista o un islamista? y, d) emblema de Obama fusionado con la bandera del arco iris: Obama quiere derogar las leyes que nos protegen contra los gays (Implicatura débil). Sabido es que Obama es un decidido defensor de los derechos de gays, lesbianas y transexuales. Basta leer sus alegatos sobre el tema, señalamos por su cercanía al momento que nos ocupa su discurso del 1 de Junio de 2009 con motivo del «Lesbian, Gay, Bisexual, and Transgender Pride Month».

\section{Aproximación pragmática al discurso del odio}

El discurso del odio (hate speech) ha sido definido por diversas instituciones estadounidenses. Una de las modalidades de deshumanización más acentuada es el racismo. Los elementos básicos del racismo estriban en su función política, su estructura teórico-moral y su desarrollo histórico-filosófico que, obviamente, no podemos desarrollar en este trabajo. Este tipo de arenga racista propiciada por la valla publicitaria tiene como propósito promover la desigualdad y la intolerancia y puede ser subdividida en cuatro áreas principales: a) el lenguaje de la disensión (divisive language) representado por el nosotros contra ellos -patriotas/antipatriotas-; b) los razonamientos malintencionados o erróneos (flawed argumentations) entre los que se incluyen la aceptación de las habladurías y de los rumores como un hecho, c) los

\footnotetext{
${ }^{34}$ Se trata de una locución latina que significa 'tú también'. Esta falacia se utiliza frecuentemente como una técnica de retórica que tiene como objetivo refutar la afirmación de un individuo desacreditándolo.
} 
argumentos ad hominem y otras falacias, los comentarios dogmáticos, la apelación a la auctoritas (de la Biblia, de los padres fundadores de la patria, de las frases de presidentes, etc.), el establecimiento de culpabilidad por asociación con hechos o declaraciones ajenas y con determinados acontecimientos luctuosos; las metáforas deshumanizadoras (deshumanizing metaphors), éstas últimas poseen intencionalidad degradante (demeanig) porque tildan a otras personas de "marginales" y "desechables" (expendable). La nacionalidad es una condición política definida por sustracción, por la etiqueta, por el apartamiento y por la conformación de la marginalidad social como desecho humano (expendable beings) $\mathrm{y}$, en cuarto lugar, d) los hechos falsos (false acts).

\section{Conclusión}

Apreciamos que la valla publicitaria que hemos seleccionado como objeto de estudio configura un discurso electoral que posee su propia identidad, como foco contextual o género, determinada por tres elementos: a) el propósito estilístico escogido para manifestar el mensaje, b) por el carácter propagandístico persuasivo tendente a la manipulación y c) por el talante agresivo que la impulsa. La potencia comunicativa de sus mensajes icónico-verbales trasciende los símbolos y formula serias transgresiones argumentativas. Se dan unas informaciones manipuladas o falsas para crear un estado de opinión propicio para un fin (intoxicación informativa). Por estas razones queda sujeta a posibles reinterpretaciones emocionales. Su estudio puede ser abordado desde la Teoría de la Relevancia como un caso práctico de traducción icónico-verbal que ayude a complementar los abundantes estudios teóricos, en muchos casos, saturados de metalenguaje así como un intento de exploración de algunos de sus elementos desde la conexión de la teoría con otras disciplinas.

Desde un punto de vista discursivo-ideológico, consideramos que estas vallas publicitarias vienen a reflejar unas creencias más o menos unificadas del papel que representa la figura del presidente Barack Obama para los extremistas de derechas (winguts). Los partidarios del Tea Party las resumen muy bien con estos dos acrósticos (backronym) de Obama: One / Big / Awful / Mistake / America (un enorme y espantoso error cometido por los estadounidenses) o éste otro: Oppressive / Bloodsucking / Arrogant / Muslim / Alien (la tiranía de una sanguijuela musulmana, extranjera y arrogante). Para los ultraconservadores el discurso del odio, es decir, la confrontación agresiva permanente con las acciones del gobierno de Obama, los ataques contra los musulmanes (islamofobia), contra los inmigrantes (xenofobia), el racismo, el sexismo y la homofobia son sus persistentes letanías. Desde esta perspectiva su comentada campaña de vallas publicitarias anti-Obama supone un intento perfectamente orquestado de desacreditación politico-publicitaria del presidente negro que persigue como objetivo político conseguir que no repita mandato -el actual finalizará en 2012-, pero al mismo tiempo nos muestran una visión palmaria de los valores que caracterizan al nacionalismo identitario y excluyente.

Desde las expectativas de los receptores, las principales variables a destacar de este tipo de propaganda político-emocional son: la credibilidad de los anuncios, la actitud hacia los mismos y las emociones evocadas por este tipo de publicidad. Watzlawick, 
Beavin y Jackson (2002) aseguran que los participantes en una interacción pueden estar de acuerdo en el significado atribuible al contenido del mensaje y, sin embargo, discrepar en el significado relacional, en la definición de la relación: «En el peor de los casos, los participantes están en desacuerdo con respecto al nivel del contenido y también de relación».

Coincidimos con S. Melo en que la traducción debe integrar el simbolismo, las metáforas visuales y la inteligencia emocional. Por éstas y otras razones, debemos asumir, también, el rol ideológico conservador del receptor afín ${ }^{35}$ al que va dirigido el mensaje, que puede ciertamente percibir los enunciados de forma relevante. Como en anteriores páginas hemos intentado mostrar alguna de las razones que han podido servir de base al emisor para aseverar a través de las caricaturas y de los lemas verbales sus razonamientos. Creemos que la mayor parte de éstos son imperfectos o erróneos (flawed arguments) y que conducen a unos juicios de valor sólo aceptables desde una cosmovisión radical de ideología afín. Desde tiempo atrás los tratadistas han considerado las falacias lógicas como un recurso eminentemente práctico, en discusiones filosóficas, jurídicas y, muy especialmente, en el terreno político. Se recurre a su empleo siempre que se pretende persuadir a alguien de algo, lo cual exige compartir con el auditorio un determinado número de premisas, aunque sea de una forma fundamentalmente teórica.

\section{Bibliografía}

Amorós, E. (2007): Comportamiento Organizacional: En Busca del Desarrollo de Ventajas Competitivas. Escuela de Economía USAT. Lambayeque - Perú.

Aparici, R.; García-Matilla, A. (1987): Lectura de imágenes. Madrid, Ediciones de la Torre.

Bello Reguera, G. (2008): «De la demonización al racismo (sobre la deshumanización del otro)». Criterio jurídico, vol. 8, nº. 2, págs. 9-24.

Casacuberta, D., Figueras, C. Y Martínez, R. (1999): «The R files: Applying Relevance Model to conspiracy theory of fallacy». Journal of English Studies I, pp. $45-55$

DíAz Pérez, F. J. (1999): «Una aproximación al uso de la metáfora en la publicidad británica y en la española desde la teoría de la relevancia». Pragmalingüística, ISSN 1133-682X, no 7, 1999, pp. 45-64.

Fresnault-Deruelle, P. (1990): «L'éloquence des images». Images fixes III, París, P.U.F.

Goffman, E. (1998): Estigma. La identidad deteriorada. Buenos Aires, Amorrortu. ISBN 950-518-016-0.

GutT, E-A. (1991): Translation and Relevance: cognition and context. Oxford: Blackwell

Herrero, J. (1997): «El eslogan publicitario y los efectos comunicativos del juego de la ambigüedad semántica». Paremia, 6. Madrid. pp. 337-341

\footnotetext{
${ }^{35}$ Sin pretender ser exhaustivos podríamos hacer una breve enumeración de los enemigos interiores de Obama en 2010: los poseedores de armas (gun owners), los antiabortistas (prolifers), los veteranos (Vets), los miembros del Partido del Té (Tea party people), los republicanos menos extremistas, algunos señalados medios escritos, conocidos comentaristas radiofónicos, determinados grupos cristianos y la masa conservadora en sentido amplio.
} 
Lakoff, G. Y Johnson M. (1995). Metáforas de la vida cotidiana. Madrid: Cátedra.

López Folgado, V. (2010) «Traducción y relevancia: ¿qué quiere decir "semejanza interpretativa" en traducción?», en Perdu Honeyman, N. Cambio de dimensiones en traducción y comunicación. Almería: Editorial Universidad de Almería. pp. 47-71.

Melo, S. (2010) «Marketing Strategies in the Global Market» Ver en www.focus.com/ briefs/marketing/marketing-translations/

Martínez Camino, G. (2008): Diferenciación pragma«lingüistica de dos tipos de publicidad: publicidad racional vs. publicidad emocional- racional. Universidad de Cantabria.

Petтiт, Arthur G. (1980): «Images of the Mexican-American in Fiction and Film», Collage Stations, California.

Pinto, M. Y Gálvez C. (1999). Análisis documental de contenido. Madrid: Síntesis.

Simpson, P. (2001): «'Reason' and 'tikle' as pragmatic constructs in the discourse of advertising», Journal of Pragmatics, 33, pp. 589-607.

SPERBER, D.; WILSON, D. (1994): La Relevancia. Comunicación y procesos cognitivos. Visor. Madrid (Trad. española de Eleanor Leonetti.).

TANAKA, K. 1994: Advertising Language. London. Routledge.

VILLEGAS, C. A.: «Enunciados declarativos y pragma-gramática». UPEL - IPC Letras, Vol 51, No 79.

Watzlawick, P., BeAvin, J. Y Jackson, D. (2002), Teoría de la Comunicación Humana. Barcelona: Herder.

Willis García-Talavera, J. F. (2002): «El significante icónico dentro de la estructura semiótica mixta del programa de mano M-G-M.» Espéculo. Revista de estudios literarios. Universidad Complutense de Madrid .

Wilson, D. Y SPERBER, D. (2004): «La Teoría de la Relevancia». Revista de Investigación Lingüistica, Vol.VII, pp. 233-282

YUSTE FRÍAS, J. (2005): «Desconstrucción, traducción y paratraducción en la era digital», en Yuste Frías J. y Álvarez Lugrís A. [eds.], Estudios sobre traducción: teoría, didáctica, profesión, Vigo, Servizo de Publicacións da Universidade de Vigo, col. T\&P, n. ${ }^{\circ} 1$, pp. $59-82$.

Yuste FríAs, J. (2011) «Leer e interpretar la imagen para traducir», Trabalhos em Lingüística Aplicada, vol.50, n. ${ }^{\circ}$ 2, (2011) pp. 257 -280. Print version ISSN 01031813.

\section{Referencias de las imágenes}

THE COLORADO BILLBOARD. http://articles.nydailynews.com/2010-10-16/ news/27078394_1_anti-obama-death-threats-gop-and-democrats 